The book's final section examines initiatives that explore how learning happens. The Carnegie Academy for the Scholarship of Teaching and Learning, the Visible Knowledge Project, the KEEP toolkit and the Learning Activity Management System are cited as examples. They do not necessarily involve much technology but use alternatives to the standard lecture format, such as discussions in small student groups. Peer review of research is standard practice, and some argue that teaching should also undergo this process. As these activities require time and effort, new teaching methods need to be given greater priority in the academic reward system before we can expect their widespread adoption. Bernadine Chuck Fong, a former president of Foothill College, California, describes the college's pioneering work in online and open education. She says that leadership is key to supporting such new initiatives: it must be made clear to faculty members that honesty, trust, integrity and forgiveness are highly valued across the institution. Many authors mention that a strong sense of community is important for the sustained sharing of teaching experiences.

For anyone interested in the openness movement or in changes to the educational system, Opening Up Education is worth perusing. The book is freely available online with links to individual chapters, making it easy to cite and share. It is not an exhaustive review of the field - more examples can be found in the blogosphere - but this valuable book highlights the leading authors on openness in education who we should follow as the field evolves.

Jean-Claude Bradley is an associate professor in the Department of Chemistry, Drexel University, Philadelphia, Pennsylvania 19104, USA.

e-mail: jean-claude.bradley@drexel.edu

\title{
Rare books in the flesh
}

\author{
Beautiful Science: \\ Ideas that Changed the World \\ Huntington Library, San Marino, California \\ Permanent exhibition
}

Authentic books, documents and models provide an inspirational introduction to the development of science. One of the world's major rare-book collections is held by the Huntington Library in San Marino, California, which has set up its first permanent exhibition about the history of science.

Beautiful Science, which opened in November, displays classic manuscripts and other artefacts relating to astronomy, biology, medicine and physics in four rooms. The original Huntington collection, which now includes the astronomy holdings of the Observatories of the Carnegie Institution of Washington, was bolstered in 2006 by the addition of 67,000 books from the Dibner family's Burndy Library. Curator Dan Lewis has selected about 100 major scientific works from the hundreds of thousands in the collection.

The astronomy room opens with two thirteenth-century manuscripts: Almagest, Ptolemy's astronomical treatise originally written in the second century AD, and an Arabic manuscript covering similar material. Edwin Hubble's own copy of Nicolaus Copernicus's De Revolutionibus, alas only the second edition from 1566 instead of the first (1543), is on show. Censored by order of the Inquisition in the early seventeenth century, the book reveals the original Sun-centred diagram. Isaac Newton's Principia Mathematica (1687) is alongside, a copy that was owned by first Newton himself and then Edmond Halley. The exhibition combines the new with the old: computer animations contrast the Ptolemaic and Copernican views of planetary orbits, and an audio stream quotes from a letter from Hubble explaining the expanding Universe. Also here is Hubble's 1923 logbook that he used at the 2.5-metre Mount

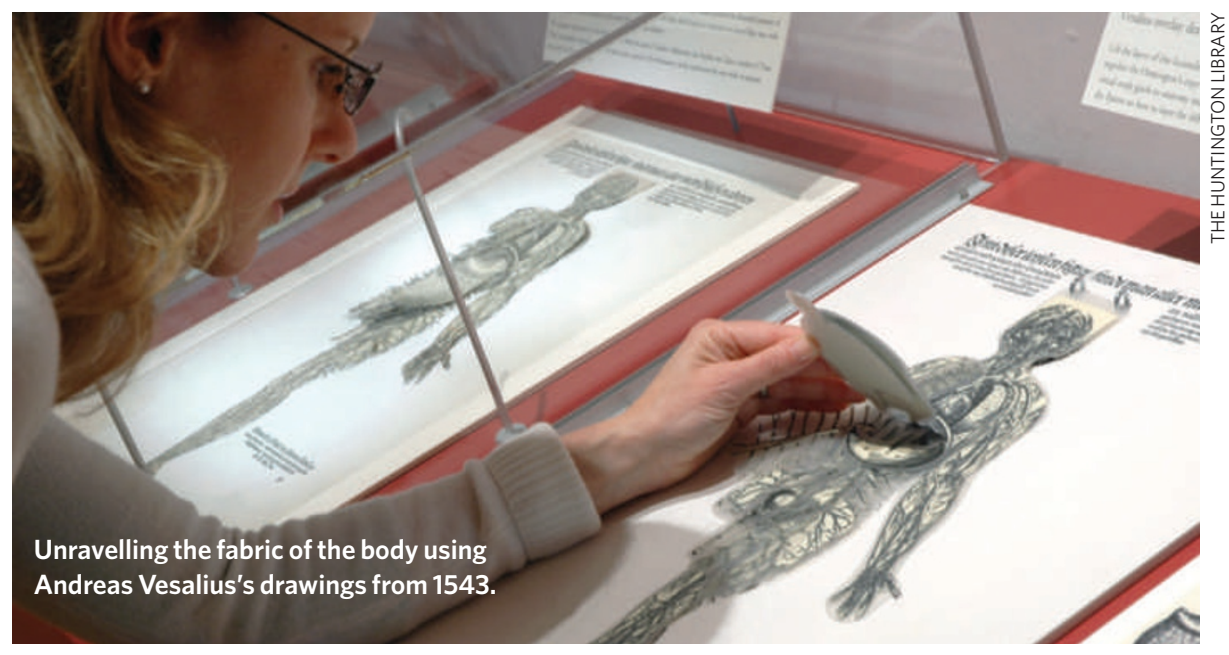

Wilson telescope near Pasadena, California. A mark shows his discovery in the Andromeda galaxy of the variable star - later found to be a supernova - that sparked our understanding of the Universe's expansion.

In the biology and natural history section lies a first edition of Charles Darwin's On the Origin of Species, with 251 editions of the book in various languages along the wall. Robert Hooke's detailed engraving of a flea in his Micrographia (1665) is accompanied by a replica microscope of the time, through which visitors can look at a real flea. Similarly displayed are Antonie von Leeuwenhoek's complete works from 1664 to 1718. Diagrams of the human body in Andreas Vesalius's oversized anatomy book from 1543 are paired with hands-on plastic versions. An unusual, small ivory model from 1540, about 15 centimetres long, shows a pregnant woman with a removable front torso.

The room devoted to physics and light hosts a collection of strangely shaped light bulbs and filaments, three labelled in Thomas Edison's handwriting. Newton's own copy of the second edition of his Opticks (1717) is accompanied by a metre-square display of his 1664 experiment: one prism breaks up white light into a rainbow of colours, and a second prism, which can be moved with a lever, recomposes it. Three spectral atlases are displayed, including Josef Fraunhofer's own from 1816, with his labelling of the strongest absorption lines in the solar spectrum with capital letters, a notation still used today. This atlas belonged to George Ellery Hale, founder of the California Institute of Technology in Pasadena and the Palomar and Mount Wilson Observatories, and who encouraged Henry Huntington to buy the extensive grounds in which the Huntington Library now stands.

The exhibition is a delight. The Huntington's botanical gardens, which are resplendent during the Californian winter, provide the ideal setting to reflect on the great moments of science collected in this fascinating exhibition.

Jay M. Pasachoff is an astronomer at the California Institute of Technology, Pasadena, California 91125, on sabbatical leave from Williams College, Williamstown, Massachusetts 01267, USA.

e-mail: jay@gps.caltech.edu 